\title{
МЕХАНИЗМ ВЛИЯНИЯ ЭЛЕКТРИЧЕСКОГО ПОЛЯ ОТРИЦАТЕЛЬНО ЗАРЯЖЕННОЙ ПОВЕРХНОСТИ ЧАСТИЦ ГИДРОСИЛИКАТНОГО ГЕЛЯ НА КОЭФФИЦИЕНТ ДИФФУЗИИ КАТИОНОВ $\mathrm{Ca}^{2+}$
}

\section{MECHANISM OF THE ELECTRIC FIELD EFFECT OF NEGATIVELY CHARGED SURFACE OF THE PARTICLES HYDROSILICATE GEL ON THE DIFFUSION COEFFICIENT OF $\mathrm{Ca}^{2+}$ CATIONS}

\author{
Представил д-р техн. наук, профессор А.А. Плугин
}

\begin{abstract}
Введение. Механизмы воздействия переменного тока на бетонные, железобетонные и каменные конструкции многогранные и очень сложные, в силу чего мнения ученых разделились и являются зачастую полярными. Одной из причин этого является специфика процессов электрокоррозии бетона, железобетона и раствора в обводненных конструкциях, не укладывающаяся в рамки традиционной электрофизики и электротехники.
\end{abstract}

Анализ предыдущих публикаций и исследований. Наличие большого количества обводненных бетонных, железобетонных и каменных конструкций мостов, тоннелей, труб и других сооружений, подверженных интенсивной электрокоррозии, многогранность и вместе с тем взаимосвязанность различных теоретических аспектов обусловили проведение критического анализа литературных источников по следующим аспектам:

- оценка в трудах ученых и нормативных документах степени опасности электрокоррозии бетона и стали от действия переменного тока;

- механизм коррозии бетона и железобетона постоянным и переменным током.
Анализ литературных данных по вопросам оценки степени опасности электрокоррозии бетона и стали под влиянием переменного тока [2,3] показал отсутствие единства взглядов ученых и требований нормативных документов. Зачастую мнения ученых и нормативные документы являются несогласующимися, а часто противоречивыми.

Исследованию механизмов электрокоррозии бетона и железобетона под влиянием постоянных и переменным токов посвящены работы [4-10]. Следует отметить, что исследованиям в этой области посвящено незначительное количество работ, что, вероятно, связано с принятым мнением о слабом влиянии на бетон постоянных токов и полном отсутствии влияния переменных токов.

\section{Целью исследования является} раскрытие механизма влияния электрического поля отрицательно заряженной поверхности частиц гидросиликатного геля на коэффициент диффузии катионов $\mathrm{Ca}^{2+}$.

Результаты исследований. В [1] представлены данные по зависимости коэффициента диффузии от В/Ц. Такая зависимость может быть обусловлена 
уменьшением вязкости граничного слоя воды у поверхности частиц гидросиликатов кальция. В свою очередь, сильное уменьшение коэффициента диффузии может быть обусловлено связыванием ионов (уменьшением подвижности), в частности катионов $\mathrm{Ca}^{2+}$, в электрическом поле отрицательно заряженной поверхности частиц гидросиликатного геля и структурированием воды в граничном слое этих частиц.

Рассмотрим более детально механизм проявления этих двух факторов.
Диффузия иона в граничном слое воды затормаживается под влиянием энергии взаимодействия между ионом $\mathrm{Ca}^{2+}$ и ПОИ $\mathrm{OH}^{-}$на поверхности гелевой частицы. Энергия этого взаимодействия [11]

$$
f_{\ni C}=\frac{z e^{2}}{4 \pi \varepsilon \varepsilon_{0} \cdot\left(\delta_{\Gamma C}\right)^{2}} .
$$

Работа, которую совершает ион при его отрыве от молекулы воды,

$$
u_{\ni C}=f \cdot\left(r_{\mathrm{H}_{2} \mathrm{O}}+r_{C a^{2+}}\right)=\frac{z e^{2} \cdot\left(r_{\mathrm{H}_{2} \mathrm{O}}+r_{C a^{2+}}\right)}{4 \pi \varepsilon \varepsilon_{0} \cdot\left(\delta_{\Gamma C}\right)^{2}}
$$

Проанализируем возможность рассмотрения природы коэффициента диффузии ионов в бетоне на основе уравнения Эйнштейна для коэффициента диффузии $D$ коллоидных частиц, а также первого закона Фика для диффузионного переноса вещества $d n_{i}[1]$

$$
D=\frac{R T}{6 \pi \cdot \eta \cdot r \cdot N_{A}}
$$

где $R T$ - универсальная газовая постоянная,

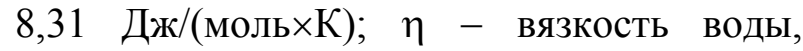
0,001 Пахс; $r$ - радиус частицы, м; $N_{A}-$ число Авогадро $\left(6,02 \times 10^{23} 1 /\right.$ моль $)$.

Применительно к 1 иону

$$
D=\frac{\kappa T}{6 \pi \cdot \eta \cdot r}
$$

По аналогии с (4.14) коэффициент диффузии катиона $\mathrm{Ca}^{2+}$ в граничном слое воды определится выражением

$$
D_{\Gamma C}=\frac{u_{\ni C}}{6 \pi \cdot \eta \cdot r_{A}}
$$

Разделим (4) на (5)

$$
\frac{D_{\Gamma C}}{D}=\frac{u_{\ni C} \cdot 6 \pi \cdot \eta \cdot r_{K A T}}{6 \pi \cdot \eta \cdot r_{K A T} \cdot \kappa T}=\frac{u_{\ni C}}{\kappa T},
$$

откуда

$$
D_{\Gamma C}=D \frac{u_{\ni C}}{\kappa T}
$$

Величину $\delta_{\Gamma \mathrm{C}}$ в уравнении (2) определим путем деления объема воды на частицах геля на площадь поверхности гидросиликатного геля

$$
\delta_{\Gamma C}=\frac{Ц \cdot\left[\frac{B}{Ц}-\alpha \cdot\left(\frac{B}{\zeta}\right)_{X C}-\frac{V_{\Pi У C}^{\Gamma}}{Ц}\right]}{\left\lfloor\alpha \gamma^{\Gamma} s^{\Gamma}\right.},
$$


где $(\mathrm{B} / Ц)_{x с}-$ водоцементное отношение, соответствующее химически связанной в цементе воде; $\alpha$ - степень гидратации цемента $(0,5) ; \gamma^{\Gamma}$ - доля гидросиликатного геля в продуктах гидратации цемента $(0,75) ; s^{\Gamma}-$ удельная поверхность гидросиликатного геля (200-700 м² г).

Пористость геля, имеющего сферическую форму частиц, можно определить геометрически по схеме рис. 1.

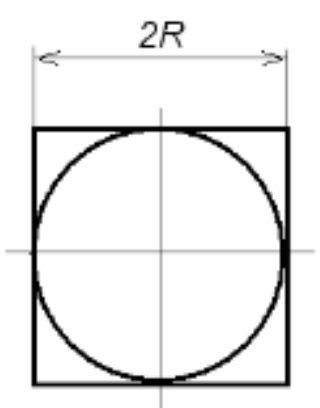

Рис. 1. Схема для определения пористости гидросиликатного геля

$$
\Pi o p^{\Gamma}=\frac{8 R^{3}-\frac{4}{3} \pi R^{3}}{8 R^{3}}=\frac{8 R^{3}-4,187 R^{3}}{8 R^{3}}=\frac{3,813}{8}=0,48
$$

Средняя плотность геля равна

$$
\rho_{C P}^{\Gamma}=\rho^{\Gamma} \cdot\left(1-\Pi o p^{\Gamma}\right),
$$

где $\rho^{\Gamma}-$ плотность гидросиликатного геля $\left(2,7 \Gamma / \mathrm{cm}^{3}[123]\right)$.
Соответственно,

$$
\rho_{C P}^{\Gamma}=2,7 \cdot(1-0,48)=1,4 \Gamma / \mathrm{cm}^{3}
$$

Выразим объем пор в геле через расход цемента

$$
\frac{V_{\Pi О P}^{\Gamma}}{Ц}=\frac{0,48 \Gamma / \rho^{\Gamma}}{Ц}=\frac{0,48 \cdot Ц \alpha \gamma^{\Gamma}}{\rho_{C P}^{\Gamma} \cdot Ц}\left(\frac{2}{2 / \mathrm{cm}^{3} \cdot 2}=\frac{\mathrm{cm}^{3}}{2}\right) .
$$

Подставим $\alpha=0,5 ; \gamma^{\Gamma}=0,75 ; s^{\Gamma}=700 \mathrm{~m}^{2}$, как для высокоосновного (наиболее дисперсного) гидросиликатного геля,

$$
\frac{V_{\Pi О P}^{\Gamma}}{Ц}=\frac{0,48 \cdot 0,5 \cdot 0,75}{1,4}=0,129\left(\frac{\mathrm{CM}^{3}}{2}\right) .
$$

Соответственно, толщина граничного слоя воды определится выражением

$$
\delta_{\Gamma C}=\frac{(B / Ц-0,5 \cdot 0,23-0,129)}{0,5 \cdot 0,75 \cdot 700 \cdot 10^{4}}\left(\frac{c M^{3} / 2}{c M^{2} / 2}\right)=3,8 \cdot 10^{-9} \cdot\left(\frac{B}{Ц}-0,25\right)(\mathcal{M})
$$

На рис. 2 представлен график изменения толщины слоя воды на поверхности частиц гидросиликатного геля в зависимости от В/Ц бетона, построенный по этому уравнению. Согласно этому графику слои воды являются очень тонкими (до 2 нм), что позволяет считать их граничными, в которых вода связана поверхностью частиц.

Упростим выражение (2): 


$$
u_{\ni C}=\frac{2 \cdot 2,56 \cdot 10^{-38} \cdot(1,4+1) \cdot 10^{-10}}{1,116 \cdot 10^{-10} \cdot \varepsilon \cdot 3,8^{2} \cdot 10^{-18} \cdot(B / Ц-0,25)^{2}}=\frac{0,76 \cdot 10^{-20}}{\varepsilon \cdot(B / Ц-0,25)^{2}} .
$$

С учетом (12) выражение (7) для $D_{\Gamma с}$ принимает вид

$$
D_{\Gamma C}=D \cdot \frac{0,76 \cdot 10^{-48}}{\varepsilon \cdot(B / Ц-0,25)^{2} \cdot \kappa T}=D \cdot \frac{0,76 \cdot 10^{-20}}{\varepsilon \cdot(B / Ц-0,25)^{2} \cdot 4,11 \cdot 10^{-21}}=D \cdot \frac{1,85}{\varepsilon \cdot(B / Ц-0,25)^{2}} .
$$

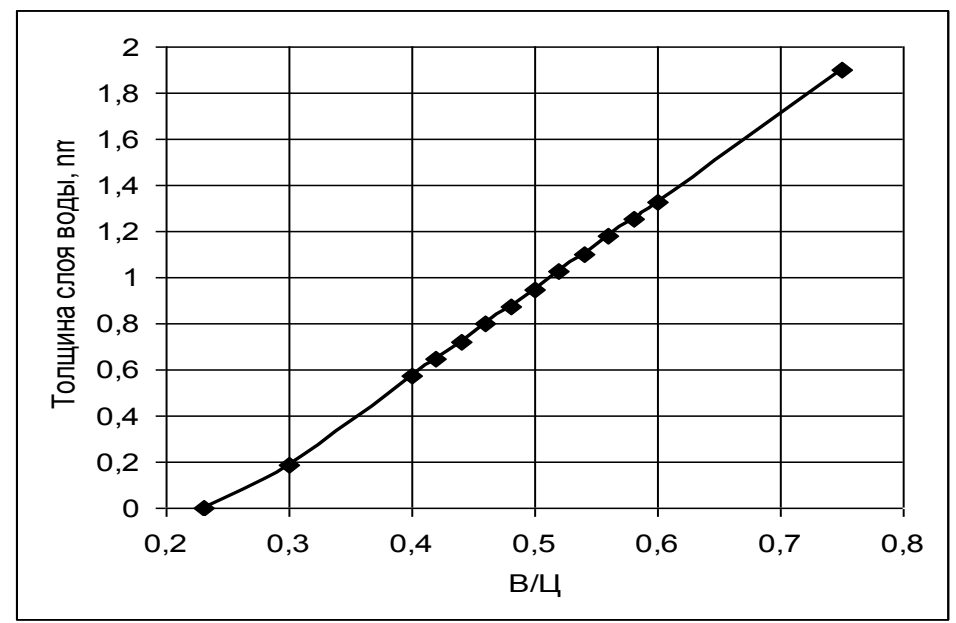

Рис. 2. Зависимость толщины слоя воды на поверхности частиц от В/Ц бетона

Вода в свободном состоянии обладает высокой диэлектрической проницаемостью, в пределах 80-81. Это обусловлено тетраэдрическим строением ее молекул с параллельным ориентированием при этом молекулярных диполей. Несмотря на значительное количество работ по образованию более крупных ассоциатов воды (кластеров), первичной ячейкой квазиструктуры воды признаются ассоциаты, содержащие от трех до шести молекул воды (триммеры, тетраметры, пентаметры и гексаметры воды).

Однако в граничном слое ее диэлектрическая проницаемость уменьшается вплоть до высокочастотной диэлектрической проницаемости, близкой к 2. Это уменьшение обусловлено структури- рующим влиянием поверхности на свойства воды [12].

Теория диэлектрической проницаемости воды объясняет ее высокое значение за счет взаимного ориентирующего влияния полярных молекул. На основе учета 5-молекулярного ассоциата с параллельными дипольными моментами молекул воды в [13] выведена формула, которая дает расчетную величину диэлектрической проницаемости воды (и других полярных жидкостей), близкую к экспериметальным результатам.

В граничных слоях на молекулы воды оказывает сильное влияние электрическое поле поверхности. Исходя из этого, выведена формула для диэлектрической проницаемости воды в граничном слое, которая имеет следующий упрощенный вид [13]:

$$
\varepsilon_{\Gamma C}=2,16+1,28 \cdot \frac{\delta}{\psi_{\ni \Pi}^{P}}\left[1-\exp \left(-\frac{75,5 \cdot \psi_{\ni \Pi}^{P}}{\delta}\right)\right],
$$


где $\delta$ - расстояние от поверхности частицы, $\AA ; \psi_{\text {эп }}^{P}-$ равновесный электроповерхностный потенциал частицы, В; 2,16 - величина высокочастотной диэлектрической проницаемости воды, т.е. предельно связанной непосредственно у поверхности частицы.

В табл. 1 и на рис. 3 представлены зависимости диэлектрической проницаемости воды в граничных слоях $\varepsilon_{\Gamma \mathrm{C}}$ от расстояний $\delta$ от поверхности для различных электроповерхностных потенциалов, характеризующих гидросиликаты кальция ГСК различной основности (чем выше абсолютная величина потенциала, тем ниже основность ГСК [13]).

Определяя и подставляя в (13) величины $\mathrm{B} / Ц$ и $\varepsilon$, выполнен расчет коэф- фициентов диффузии катионов $\mathrm{Ca}^{2+}$ в бетонах для $D=1,15 \mathrm{~cm}^{2} / \mathrm{c}$ (для концентрации гидроксида кальция в бетоне 0,02 моль/л, табл. 2). По данным этой таблицы построен соответствующий график изменения $D_{\text {Гс }}$ для различных В/Ц бетона (рис. 4 , сплошная линия - расчетная зависимость, пунктирная линия экспериментальная).

Высокая степень совпадения расчетной кривой, как по характеру изменения, так и по абсолютным величинам, с экспериментальными данными для бетона свидетельствует о корректности количественного описания механизма диффузии катионов $\mathrm{Ca}^{2+}$ в граничном слое воды.

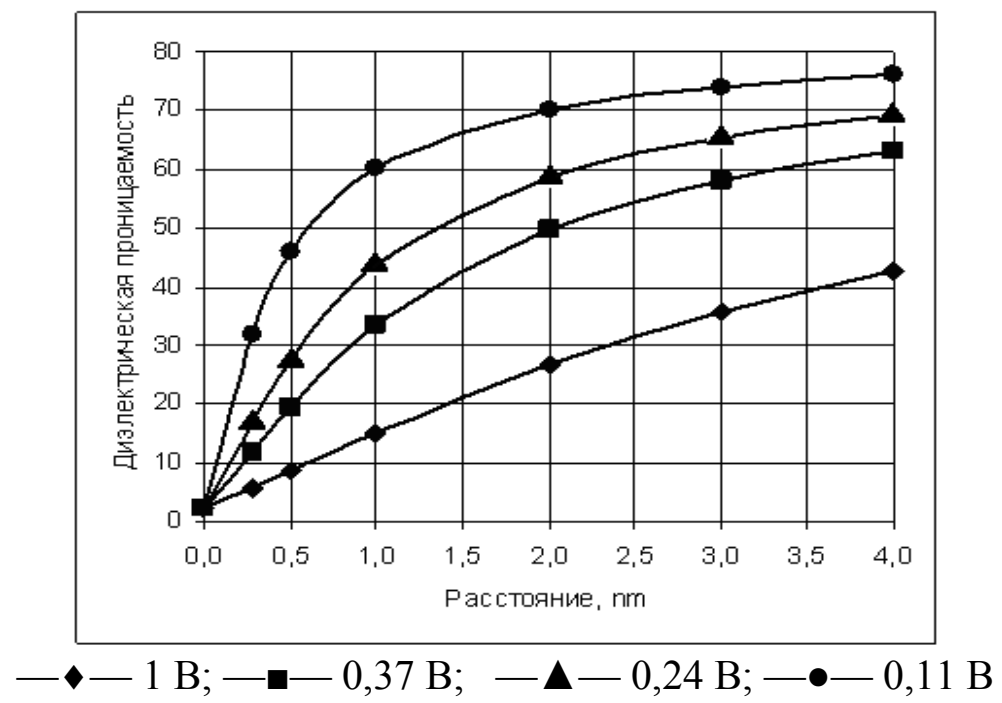

Рис. 3. Зависимость $\varepsilon$ воды в граничных слоях от расстояния до поверхности частиц

Таблица 1

Данные расчета диэлектрической проницаемости воды в граничном слое по формуле (14)

без учета водородных связей

\begin{tabular}{|c|c|c|c|c|}
\hline \multirow{2}{*}{$\begin{array}{c}\text { Расстояние, } \\
\text { нм }\end{array}$} & \multicolumn{4}{|c|}{ Равновесный электроповерхностный потенциал $\psi_{\text {эп }}^{P} \mathrm{~B}$} \\
\cline { 2 - 5 } & $1 \mathrm{~B}$ & 0,37 & 0,24 & 0,11 \\
\hline 1 & 2 & 3 & 4 & 5 \\
\hline 0,0 & 2,2 & 2,2 & 2,2 & 2,2 \\
\hline 0,3 & 5,7 & 11,8 & 17,0 & 32,0 \\
\hline 0,5 & 8,6 & 19,3 & 27,5 & 45,8 \\
\hline 1,0 & 14,9 & 33,4 & 43,7 & 70,3 \\
\hline 2,0 & 26,7 & 49,7 & 58,7 & 74,0 \\
\hline 3,0 & 35,8 & 58,2 & 65,4 & \\
\hline
\end{tabular}


Продолжение табл. 1

\begin{tabular}{|c|c|c|c|c|}
\hline 1 & 2 & 3 & 4 & 5 \\
\hline 4,0 & 42,7 & 63,2 & 69,2 & 76,1 \\
\hline 5,0 & 48,0 & 66,5 & 71,6 & 77,3 \\
\hline 10,0 & 61,9 & 74,0 & 76,9 & 79,9 \\
\hline 20,0 & 71,2 & 78,1 & 79,7 & 81,3 \\
\hline 30,0 & 74,8 & 79,6 & 80,7 & 81,7 \\
\hline 40,0 & 76,6 & 80,4 & 81,2 & 82,0 \\
\hline 50,0 & 77,8 & 80,8 & 81,4 & 82,1 \\
\hline 60,0 & 78,6 & 81,1 & 81,6 & 82,2 \\
\hline 80,0 & 79,6 & 81,5 & 81,9 & 82,3 \\
\hline 100,0 & 80,2 & 81,7 & 82,0 & 82,4 \\
\hline
\end{tabular}

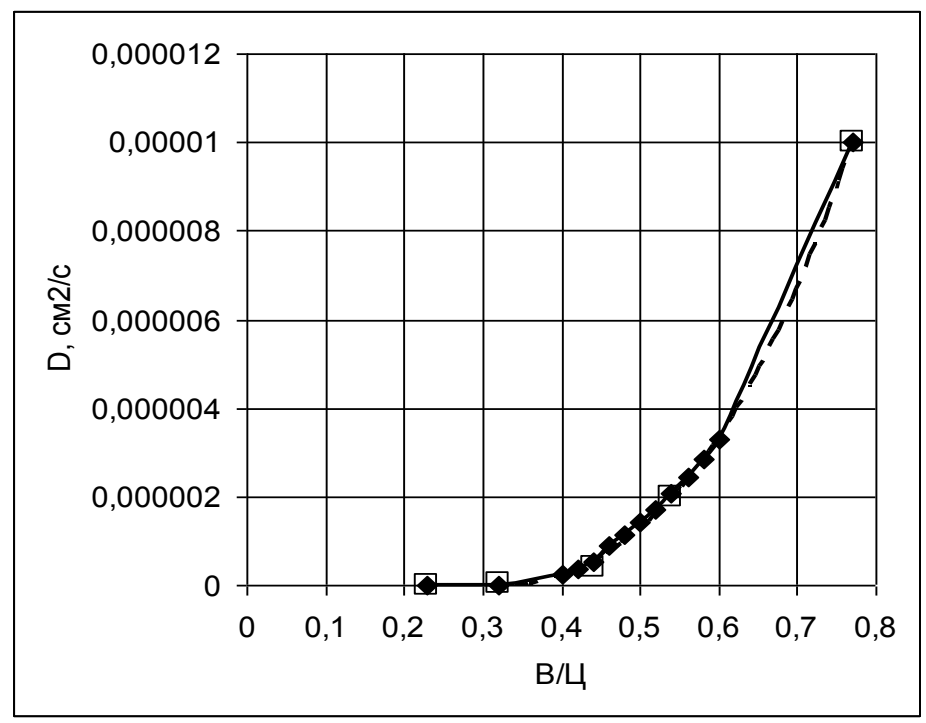

$\longrightarrow$ - расчетная кривая; ——— данные СНиП и экспериментальные из литературных источников [14]

Рис. 4. Зависимость коэффициента диффузии бетона от В/Ц

Таблица 2

Расчетные и экспериментальные величины коэффициента диффузии ионов $\mathrm{Ca}^{2+}$ в бетоне с различными В/Ц

\begin{tabular}{|c|c|c|c|c|c|}
\hline В/Ц & $\begin{array}{c}D_{\text {Гс, }} \\
\text { (расчетная), } \mathrm{cm}^{2} / \mathrm{c}\end{array}$ & $\begin{array}{c}D \text { бетона, } \\
\mathrm{cm}^{2} / \mathrm{c}\end{array}$ & В/Ц & $\begin{array}{c}D_{\text {Гс, }} \\
\text { (расчетная) }, \mathrm{cm}^{2} / \mathrm{c}\end{array}$ & D бетона, $\mathrm{cm}^{2} / \mathrm{c}^{-6}$ \\
\hline 0,23 & $4,5954 \mathrm{E}-10$ & 0 & 0,5 & $1,41215 \times 10^{-6}$ & \\
\hline 0,32 & $1,9529 \mathrm{E}-08$ & 0,000000051 & 0,52 & $1,7181 \times 10^{-6}$ & \\
\hline 0,40 & $2,34297 \mathrm{E}-07$ & & 0,54 & $2,05724 \times 10^{-6}$ & 0,000002 \\
\hline 0,42 & $3,57952 \mathrm{E}-07$ & & 0,56 & $2,42988 \times 10^{-6}$ & \\
\hline 0,44 & $5,13506 \mathrm{E}-07$ & 0,0000004 & 0,58 & $2,83624 \times 10^{-6}$ & \\
\hline 0,46 & $8,98318 \mathrm{E}-07$ & & 0,6 & $3,27652 \times 10^{-6}$ & \\
\hline 0,48 & $1,13904 \mathrm{E}-06$ & & 0,77 & $1,00137 \times 10^{-5}$ & 0,00001 \\
\hline
\end{tabular}


Выводы и перспективы использования. Выявленный и представленный количественно механизм влияния электрического поля отрицательно заряженной поверхности частиц гидросиликатного геля на коэффициент диффузии катионов $\mathrm{Ca}^{2+}$ в граничном слое воды даёт возможность рассмотрения процессов, которые происходят в обводнённых бетонных, железобетонных и каменных конструкциях, которые включены в цепь переменного тока «рельс-земля».

\section{Список литературы}

1. Дудин, А.А. Усовершенствование классификации бетонов по водопроницаемости [Текст] / А.А. Дудин // Науковий вісник будівництва. - Харків: ХДТУБА; ХОТВ АБУ, 2013. - Вип. 71. - С. 268-272.

2. ДБН В.2.3-14:2006 Споруди транспорту. Мости та труби. Правила проектування [Текст] / НТУ. - К.: Мінбудархжиткомгосп, 2006. - 359 с.

3. ЦЭ 3551 Инструкция по защите железнодорожных подземных сооружений от коррозии блуждающими токами [Текст] / МПС СССР. - М.: Транспорт, 1979. - 89 с.

4. Плугин, Ал.А. Влияние постоянного тока на бетон обводненных конструкций и сооружений, расположенных вблизи электрифицированных железнодорожных путей [Текст]: дисс. ... канд. техн. наук / Ал.А. Плугин. - Харьков: УкрГАЖТ, 2010. - 256 с.

5. Борзяк, О.С. Механизм электрокоррозии бетона железобетонных конструкций в сложных условиях эксплуатации [Текст]: дисс. ... канд. техн. наук / О.С. Борзяк. - Харьков: УкрГАЖТ, 2010. - 240 с.

6. The NACE Annual Conference and Corrosion Show, 11-15.03.1995, Cincinnati Convention Center, Cincinnati, Ohio. - 1995. - P.519.

7. Старосельский, А.А. Коррозия и долговечность железобетона в условиях электрических воздействий [Текст]: дисс. ... д-ра техн. наук / А.А. Старосельский. - Харьков: ХИИТ, 1989. - 282 с.

8. Котельников, А.В. Блуждающие токи электрифицированного транспорта [Текст] / А.В. Котельников. - М.: Транспорт, 1986. - 279 с.

9. Старосельский, А.А. Электрокоррозия железобетона [Текст] / А.А. Старосельский. К.: Будівельник, 1978. - 168 с.

10. Артамонов, В.С. Защита от коррозии железобетона транспортных сооружений [Текст] / В.С. Артамонов, Г.М. Молгина. - М.: Стройиздат, 1976. - 192 с. $272 \mathrm{c}$.

11. Губкин, А.Н. Физика диэлектриков [Текст] / А.Н. Губкин. - М.: Высшая школа, 1971. -

12. Багоцкий, В.С. Основы электрохимии [Текст] / В.С. Багоцкий. - М.: Химия, 1988. $400 \mathrm{c}$.

13. Плугин, А.Н. Электрогетерогенные взаимодействия при твердении цементных вяжущих [Текст]: дисс. ... д-ра хим. наук / А.Н. Плугин. - Харьков: ХИИТ, 1989. - 282 с.

14. Технология изготовления железобетонных шпал [Электронный ресурс]. www.rostov-invest.ru/index.php?id=2.

Ключевые слова: механизм, бетон, цемент, диффузия, вода, расчет.

\section{Аннотации}

Наведено механізм впливу електричного поля негативно зарядженої поверхні часток гідросилікатного гелю на коефіцієнт дифузії катіонів $\mathrm{Ca}^{2+}$. Виведено формулу для 
діелектричної проникності води в граничному шарі. Представлено залежності діелектричної проникності води в граничних шарах від відстаней від поверхні для різних електроповерхневих потенціалів, що характеризують гідросилікати кальцію ГСК різної основності. Розраховано величини коефіцієнта дифузії іонів $\mathrm{Ca}^{2+}$ у бетоні з різними В/Ц.

Представлен механизм влияния электрического поля отрицательно заряженной поверхности частиц гидросиликатного геля на коэффициент диффузии катионов $\mathrm{Ca}^{2+}$. Выведена формула для диэлектрической проницаемости воды в граничном слое. Представлены зависимости диэлектрической проницаемости воды в граничных слоях от расстояний от поверхности для различных электроповерхностных потенциалов, характеризующих гидросиликаты кальция ГСК различной основности. Рассчитаны величины коэффициента диффузии ионов $\mathrm{Ca}^{2+}$ в бетоне с различными В/Ц.

Represent the mechanism of the effect of the electric field of a negatively charged particle surface hydrosilicate gel on the diffusion coefficient of the cations $\mathrm{Ca}^{2+}$. The formula for the dielectric constant of the water in the boundary layer. The dependencies of the dielectric constant of the water in the boundary layers of the distance from the surface for different surface electrical potentials characterizing calcium hydrosilicates GSK different basicity. The values of the diffusion coefficient of $\mathrm{Ca}^{2+}$ in the concrete with different W/C. 